\title{
Efeito do Déficit Hídrico na EFiciênCIa de Herbicidas e nas CaRACTERÍsticas BIOQUímiCAS DE Ipomoea grandifolia ${ }^{1}$
}

\author{
Effect of Water Stress on the Efficiency of Herbicides and on the Biochemical Characteristics of \\ Ipomoea grandifolia
}

\author{
VITORINO, H.S. ${ }^{2}$ e MARTINS, D. ${ }^{3}$
}

\begin{abstract}
RESUMO - O objetivo deste estudo foi avaliar a eficácia dos herbicidas inibidores da ALS e PROTOX no controle de Ipomoea grandifolia sob dois níveis de déficit hídrico, bem como determinar a influência desse déficit hídrico sobre o conteúdo de carboidratos solúveis, proteínas totais e aminoácidos livres da planta daninha. O trabalho foi conduzido em casa de vegetação, no delineamento experimental inteiramente casualizado, com os tratamentos dispostos em esquema fatorial 4 × 2, sendo quatro herbicidas (fomesafen, lactofen, chlorimuron-ethyl e imazethapyr) e dois niveis de déficit hídrico (com e sem déficit: -0,5 MPa e -0,01 MPa, respectivamente). Aos 7, 14, 21 e 28 dias após a aplicação, o controle foi avaliado de forma visual, e a determinação dos solutos orgânicos foi feita 24, 48, 72 e 96 horas após a aplicação dos herbicidas. À exceção de chlorimuron-ethyl, os demais herbicidas controlaram eficientemente I. grandifolia. A eficiência de controle dos herbicidas foi afetada pela condição de déficit hídrico. Os herbicidas elevaram o conteúdo de carboidratos solúveis, independentemente da condição hídrica, e proporcionaram redução de proteínas solúveis nas plantas de I. grandifolia, bem como aumentaram as concentrações de aminoácidos livres.
\end{abstract}

Palavras-chave: aminoácidos, carboidratos, controle químico, estresse, proteínas.

ABSTRACT - The objective of this work was to evaluate the efficacy of ALS and PROTOX inhibiting herbicides in the control of Ipomoea grandifolia under two levels of water deficit, as well as to determine the influence of drought on the content of the soluble carbohydrates, protein and free amino acids of the weed. The study was conducted in a greenhouse in a completely randomized design with treatments in a factorial scheme $4 \times 2$, with four herbicides (fomesafen, lactofen, chlorimuron-ethyl and imazethapyr), and two levels of water deficit (with and without deficit, $0.5 \mathrm{MPa}$ and-0.01 MPa, respectively). At 7, 14, 21, and 28 days after application, the control was evaluated visually and organic solutes were determined 24, 48, 72 and 96 hours after herbicide application. Except for chlorimuron-ethyl, the herbicides effectively controlled I. grandifolia. The control efficiency of the herbicides was affected by the water deficit condition. The herbicides increased the soluble carbohydrate content, regardless of the water status and reduced the soluble proteins in the I. grandifolia plants, also increasing the concentrations of free amino acids.

Keywords: amino acids, carbohydrates, chemical control, stress, proteins.

\section{INTRODUÇÃO}

Existem muitos componentes do meio que afetam negativamente a produção agrícola, sendo as plantas daninhas um dos fatores mais importantes, os quais estão relacionados às interferências diretas, como competição com as culturas por nutrientes, luz, água e espaço, além do efeito alelopático causado por algumas delas. Quando as plantas daninhas atuam como hospedeiras de pragas, doenças e nematoides, elas assumem importante papel

Recebido para publicação em 5.4.2011 e aprovado em 28.10.2011.

2 Engo-Agro ${ }^{-}$, Doutorando em Agronomia, Faculdade de Ciências Agronômicas, Universidade Estadual Paulista “Júlio de Mesquita Filho” - FCA/UNESP, Caixa Postal 237, 18610-307 Botucatu-SP, <vitorinohermeson@gmail.com>; ${ }^{3}$ Professor Adjunto, Dep. de Produção Vegetal, FCA/UNESP, Botucatu-SP. 
nas interferências indiretas às plantas cultivadas, assim como nas práticas culturais na colheita e em canais de irrigação, por exemplo. De acordo com Voll et al. (2002), para uma redução de $10 \%$ na produção da cultura da soja, são necessárias três plantas $\mathrm{m}^{-2}$ de Ipomoea grandifolia.

Condições ambientais pouco favoráveis, como umidade excessiva, temperatura pouco propícia, fertilidade desfavorável, elevada salinidade do solo, estresse hídrico, acidez e alcalinidade, podem interferir na germinação, no crescimento, no desenvolvimento e na reprodução de plantas daninhas.

Todos esses fatores ambientais podem acarretar mudanças nas estruturas das plantas e na sua composição, o que posteriormente poderá mudar a penetração, absorção e translocação de herbicidas, pois podem induzir aumento da pilosidade, de estômatos e do número de células buliformes, que estão envolvidas no mecanismo de enrolamento e desenrolamento de folhas, bem como na síntese de cutícula, com consequente aumento do caráter lipofilico da superficie foliar (Roman et al., 2005), o que pode alterar a ação de herbicidas.

A ocorrência do déficit hídrico é uma situação comum à produção de muitas culturas, podendo acarretar impacto negativo substancial no crescimento e desenvolvimento das plantas (Lecoeur \& Sinclair, 1996); assim, existe um conflito entre a conservação da água pela planta e a taxa de assimilação de $\mathrm{CO}_{2}$ para produção de carboidratos (Taiz \& Zeiger, 2004). A deficiência hídrica provoca alterações no comportamento vegetal, cuja irreversibilidade vai depender do genótipo, da duração e severidade do estresse e do estádio de desenvolvimento da planta.

Quando as plantas estão sob estresses impostos pelo ambiente, podem ocorrer mudanças morfológicas. Sob estresse hídrico, a cutícula das folhas desidrata, e isso potencialmente reduz a absorção de herbicidas, resultando assim em possivel menor fitotoxicidade à cultura e menor eficiência do herbicida no controle da planta daninha (Peregoy et al., 1990).

Em um estudo com plantas de Brachiaria decumbens no qual se aplicaram herbicidas inibidores da ACCase, Pereira (2010) observou que houve menor controle destas quando mantidas sob estresse hídrico, o que foi no máximo de $80 \%$ - proporcionado pelo herbicida haloxyfop-methyl. Já, Roman et al. (2005), trabalhando com plantas de Euphorbia heterophylla, observaram decréscimo no controle quando o herbicida carfentrazone-ethyl foi aplicado no tratamento não irrigado. Assim, torna-se importante conhecer como o déficit hídrico pode influenciar a ação de herbicidas no controle de plantas daninhas.

Nesse contexto, o objetivo deste trabalho foi estudar o efeito de herbicidas inibidores da ALS e PROTOX aplicados em pós-emergência em plantas de Ipomoea grandifolia, quando submetidas a déficit hídrico, bem como a ação destes sobre algumas características bioquímicas das plantas.

\section{MATERIAL E MÉTODOS}

O estudo foi realizado em casa de vegetação mantida a $26^{\circ} \mathrm{C}$, alocada no Núcleo de Pesquisas Avançadas em Matologia - NUPAM, pertencente à FCA/UNESP, campus de Botucatu. O solo utilizado no experimento foi coletado na camada arável de um Latossolo Vermelho-Escuro distrófico (Embrapa, 1999), textura franco-arenosa (Carvalho et al., 1983), da Fazenda Experimental Lajeado, da universidade.

Foram semeadas 10 sementes de Ipomoea grandifolia por vaso, porém no início da emergência foi deixada apenas uma planta por vaso, para o estudo da eficiência de controle, e duas plantas por vaso, para o estudo de solutos orgânicos. Foi determinada a umidade gravimétrica da terra por meio da pesagem do vaso após o encharcamento deste.

As condições hídricas utilizadas no experimento foram: a) capacidade de campo, no qual a umidade do solo encontrava-se a $14 \%$ (-0,01 MPa) - solo sem déficit hídrico; e b) solo com déficit hídrico, em que a umidade do solo se encontrava a $9 \%(-0,5 \mathrm{MPa})$ de acordo com a curva de retenção.

O estudo de eficiência de controle das plantas de $I$. grandifolia, bem como a avaliação do conteúdo de solutos orgânicos, foram instalados no delineamento inteiramente casualizado, com os tratamentos dispostos em 
esquema fatorial 4 (herbicidas) x 2 (niveis de estresse), com quatro repetições, para o estudo da eficiência de controle e oito repetições, para as análises de solutos orgânicos. O estudo foi conduzido no período de $8 / 3$ a 21/5/2010.

Os herbicidas utilizados foram fomesafen (250 $\mathrm{g} \mathrm{ha}^{-1}+$ Agral 0,1\% v/v), lactofen (180 $\left.\mathrm{g} \mathrm{ha}^{-1}\right)$, chlorimuron-ethyl (80 $\mathrm{g} \mathrm{ha}^{-1}+$ Assist $0,5 \% \mathrm{v} / \mathrm{v})$ e imazethapyr $\left(100 \mathrm{~g} \mathrm{ha}^{-1}\right)$, além de uma testemunha sem aplicação de herbicida para cada condição hídrica. A aplicação dos herbicidas foi feita em 23/4/2010; no momento da aplicação, as plantas daninhas apresentavam-se com quatro a seis pares de folhas definitivas.

Os tratamentos químicos foram aplicados utilizando-se pulverizador costal, pressurizado a $\mathrm{CO}_{2}$, regulado para proporcionar consumo de calda de $200 \mathrm{~L} \mathrm{ha}^{-1}$. A barra de aplicação foi constituída de duas pontas do tipo jato plano Teejet XR 11002 VS, distanciados $50 \mathrm{~cm}$ entre si.

As avaliações visuais de controle foram realizadas aos $7,14,21$ e 28 dias após a aplicação dos tratamentos (DAA), através de escala de percentual de notas, em que 0 (zero) correspondeu a nenhuma injúria demonstrada pelas plantas e 100 (cem) à morte das plantas, segundo a SBCPD (1995).

Quanto às análises bioquímicas (carboidratos solúveis, proteínas solúveis e aminoácidos livres), coletaram-se as plantas nas primeiras horas da manhã, às 24, 48, 72 e 96 horas após a aplicação (HAA); apenas para a análise de aminoácidos não foi realizada a coleta às
24 HAA. Posteriormente, o material foi liofilizado e macerado, para determinação das análises bioquímicas. As análises de carboidratos solúveis foram realizadas conforme Dubois et al. (1956); as proteínas solúveis, de acordo com Bradford (1976); e os aminoácidos livres, segundo a metodologia proposta por Yemm \& Cocking (1955).

Todos os dados foram submetidos à análise de variância pelo teste $F$, e as suas médias, comparadas entre si pelo teste de Tukey, com $\mathrm{p} \leq 0,05$.

\section{RESULTADOS E DISCUSSÃO}

Ao analisar a interação entre herbicida e condição hídrica, nota-se, aos $7 \mathrm{DAA}$, que o herbicida fomesafen proporcionou o maior controle na condição sem estresse, porém, com o déficit, esse controle foi reduzido (Tabela 1). Aos 14 DAA, o fomesafen continuou sendo o herbicida mais eficiente nas duas condições hídricas, e o mesmo se repetiu aos 21 DAA. Aos 28 DAA, tanto o fomesafen quanto o lactofen proporcionaram controle elevado das plantas de I. grandifolia, independentemente da condição de déficit hídrico.

Os inibidores da ALS não controlaram essa planta daninha satisfatoriamente, e o chlorimuron-ethyl foi mais afetado pelo déficit hídrico do que o imazethapyr. Uma infestação de I. grandifolia em soja sob déficit hídrico e que receba a aplicação de herbicidas inibidores da ALS poderá não ser bem controlada e ter o seu rendimento comprometido de forma

Tabela 1 - Controle de Ipomoea grandifolia em diferentes épocas de avaliação, sob interação entre herbicidas e condição hídrica do solo. Botucatu-SP, 2010

\begin{tabular}{|c|c|c|c|c|c|c|c|c|c|}
\hline \multirow{4}{*}{ Herbicida } & \multirow{4}{*}{$\begin{array}{c}\text { Dose } \\
\left(\text { g i.a. } \text { ha }^{-1}\right)\end{array}$} & \multicolumn{8}{|c|}{ (\%) de Controle } \\
\hline & & \multicolumn{2}{|c|}{$7 \mathrm{DAA}$} & \multicolumn{2}{|c|}{14 DAA } & \multicolumn{2}{|c|}{$21 \mathrm{DAA}$} & \multicolumn{2}{|c|}{28 DAA } \\
\hline & & \multicolumn{8}{|c|}{ Condição hídrica } \\
\hline & & $\mathrm{SE}$ & $\mathrm{CE}$ & SE & $\mathrm{CE}$ & SE & $\mathrm{CE}$ & $\mathrm{SE}$ & $\mathrm{CE}$ \\
\hline fomesafen $^{\underline{1}}$ & 250 & $82 \mathrm{aA}$ & $47 \mathrm{aB}$ & $95 \mathrm{aA}$ & $90 \mathrm{aA}$ & $97 \mathrm{aA}$ & $92 \mathrm{aA}$ & $97 \mathrm{aA}$ & $91 \mathrm{aA}$ \\
\hline lactofen & 180 & $23 \mathrm{bA}$ & $24 \mathrm{bA}$ & $57 \mathrm{bA}$ & $56 \mathrm{bA}$ & $67 \mathrm{bA}$ & $71 \mathrm{abA}$ & $91 \mathrm{abA}$ & $90 \mathrm{aA}$ \\
\hline chlorimuron-ethyl ${ }^{2 /}$ & 80 & $41 \mathrm{bA}$ & $56 \mathrm{aA}$ & $71 \mathrm{bA}$ & $66 \mathrm{bA}$ & $74 \mathrm{bA}$ & $59 \mathrm{bA}$ & $71 \mathrm{cA}$ & $44 \mathrm{cB}$ \\
\hline imazethapyr & 100 & $21 \mathrm{bA}$ & $17 \mathrm{bA}$ & $60 \mathrm{bA}$ & $28 \mathrm{cB}$ & $60 \mathrm{bA}$ & $54 \mathrm{bA}$ & $80 \mathrm{bcA}$ & $76 \mathrm{bA}$ \\
\hline $\mathrm{CV}(\%)$ & - & \multicolumn{2}{|c|}{26,9} & \multicolumn{2}{|c|}{12,4} & \multicolumn{2}{|c|}{15,5} & \multicolumn{2}{|c|}{8,4} \\
\hline
\end{tabular}

${ }^{1 /}$ Adicionou-se Agral $(0,1 \% \mathrm{v} / \mathrm{v}) ;{ }^{2}$ Adicionou-se Assist (0,5\% v/v). Médias seguidas de mesma letra minúscula na coluna e maiúsculas na linha, dentro de uma mesma época de avaliação, não diferem entre si pelo teste de Tukey ( $\leq \leq 0,05)$. SE - sem déficit hídrico; CE - com déficit hídrico; DAA - Dias após a aplicação. 
mais drástica do que se recebesse a pulverização de herbicidas inibidores da PROTOX. Voll et al. (2002) verificaram que apenas 3 plantas $\mathrm{m}^{-2}$ de I. grandifolia seria suficiente para reduzir a produção da cultura da soja em $10 \%$.

O conteúdo de carboidratos solúveis nas plantas de I. grandifolia não sofreu alteração pelos herbicidas testados às 24 horas após a aplicação (HAA) (Tabela 2). Às 48 HAA, apenas o herbicida imazethapyr proporcionou conteúdo de carboidratos solúveis maior em relação à testemunha.

Segundo Morgan (1984), um dos mecanismos de adaptação à seca é o acúmulo de solutos orgânicos osmoticamente ativos na célula, em relação às plantas bem hidratadas, fenômeno esse chamado de ajuste osmótico, que permite a manutenção da turgescência, crescimento e fotossintese sob baixos valores de potencial hídrico.

$\mathrm{Na}$ avaliação realizada às 72 HAA houve inversão de resultados, pois o efeito dos herbicidas inibidores da PROTOX elevou o conteúdo de carboidratos solúveis nas plantas de I. grandifolia, quando comparados com os encontrados na testemunha e as plantas tratadas com os herbicidas inibidores da ALS. Ao final das avaliações (96 HAA), o conteúdo de carboidratos solúveis, entre as plantas tratadas com herbicida, foi semelhante e as plantas tratadas com o chlorimuron-ethyl apresentaram mais carboidratos solúveis do que a testemunha.

$\mathrm{Na}$ análise feita às 24 HAA, o déficit aumentou o conteúdo de carboidratos cerca de
$8 \%$ em relação ao tratamento sem estresse. O déficit hídrico alterou o conteúdo de carboidratos solúveis nas plantas de $I$. grandifolia tratadas com os herbicidas testados, com exceção da avaliação efetuada às 48 HAA (Tabela 3). Segundo Bray (1997), isso se deve ao fato de que, com a diminuição do nível de água do solo, a planta responde osmoticamente com o aumento do conteúdo de carboidratos, para adaptarse ou ajustar-se ao ambiente com falta de água.

$\mathrm{Na}$ avaliação de 72 HAA, o aumento foi de $7 \%$, às 96 HAA, esse aumento foi maior, próximo a $8,5 \%$. De acordo com Pimentel (1999), o aumento no conteúdo de carboidratos solúveis pode ocorrer no início do estresse hídrico por dois motivos: em decorrência da paralisação do crescimento com certa manutenção da fotossintese; e com a intensidade do déficit hídrico, em função da hidrólise do amido.

O aumento no conteúdo de carboidratos denominado de ajuste osmótico (Munns, 2002), tem sido verificado em várias espécies

Tabela 3 - Carboidratos solúveis em plantas de Ipomoea grandifolia submetidas à aplicação de herbicidas sob duas condições hídricas. Botucatu-SP, 2010

\begin{tabular}{|l|c|c|c|c|}
\hline \multirow{2}{*}{ Condição hídrica } & \multicolumn{4}{|c|}{$\begin{array}{c}\text { Carboidratos solúveis } \\
\text { (mg g-1 }\end{array}$} \\
\cline { 2 - 5 } & 24 HAAsa seca $)$ \\
\hline Sem estresse & $1,19 \mathrm{~b}$ & $1,82^{\mathrm{ns}}$ & $1,79 \mathrm{~b}$ & $1,89 \mathrm{~b}$ \\
\hline Com estresse & $1,30 \mathrm{a}$ & 1,94 & $1,93 \mathrm{a}$ & $2,06 \mathrm{a}$ \\
\hline \multicolumn{1}{|c|}{ CV (\%) } & 12,0 & 12,4 & 7,9 & 10,0 \\
\hline
\end{tabular}

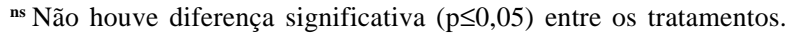
Médias seguidas de mesma letra não diferem entre si pelo teste de Tukey $(\mathrm{p} \leq 0,05)$. HAA - horas após a aplicação.

Tabela 2 - Carboidratos solúveis em plantas de Ipomoea grandifolia após a aplicação de herbicidas em diferentes épocas de avaliação. Botucatu-SP, 2010

\begin{tabular}{|c|c|c|c|c|c|}
\hline \multirow{3}{*}{ Herbicida } & \multirow{3}{*}{$\begin{array}{c}\text { Dose } \\
\left(\text { g i.a. } \text { ha }^{-1}\right)\end{array}$} & \multicolumn{4}{|c|}{ Carboidratos solúveis } \\
\hline & & \multicolumn{4}{|c|}{$\left(\mathrm{mg} \mathrm{g}^{-1}\right.$ massa seca) } \\
\hline & & $24 \mathrm{HAA}$ & 48 HAA & $72 \mathrm{HAA}$ & 96 HAA \\
\hline testemunha & - & $1,19^{\mathrm{ns}}$ & $1,77 \mathrm{bc}$ & $1,71 \mathrm{~b}$ & $1,79 \mathrm{~b}$ \\
\hline fomesafen $^{1 /}$ & 250 & 1,19 & $1,63 \mathrm{c}$ & $2,09 \mathrm{a}$ & $1,92 \mathrm{ab}$ \\
\hline lactofen & 180 & 1,34 & $1,87 \mathrm{abc}$ & $2,11 \mathrm{a}$ & $1,99 \mathrm{ab}$ \\
\hline${\text { chlorimuron-ethyl } 1^{2 /}}^{\prime}$ & 80 & 1,25 & $2,01 \mathrm{ab}$ & $1,71 \mathrm{~b}$ & $2,12 \mathrm{a}$ \\
\hline imazethapyr & 100 & 1,28 & $2,11 \mathrm{a}$ & $1,71 \mathrm{~b}$ & $2,03 \mathrm{ab}$ \\
\hline $\mathrm{CV}(\%)$ & - & 12,0 & 12,4 & 7,9 & 10,0 \\
\hline
\end{tabular}

${ }^{n s}$ Não houve diferença significativa $(\mathrm{p} \leq 0,05)$ entre os tratamentos. ${ }^{1 /}$ Adicionou-se Agral $(0,1 \% \mathrm{v} / \mathrm{v})$; ${ }^{2} /$ Adicionou-se Assist $(0,5 \% \mathrm{v} / \mathrm{v})$. Médias seguidas de mesma letra não diferem entre si pelo teste de Tukey ( $\leq 0,05)$. HAA - horas após a aplicação. 
(Morgan, 1984), sendo considerado um dos mais eficazes para manutenção da turgescência celular, pois permite principalmente a abertura estomática e fotossintese mesmo sob condições de baixo potencial hídrico no solo (Funkhouser et al., 1994; Kramer, 1995).

Os teores de proteínas solúveis nas plantas de I. grandifolia foram reduzidos após a aplicação dos herbicidas inibidores da PROTOX, aos 96 DAA (Tabela 4). Esse resultado corrobora o trabalho de Nemat Alla et al., (2008) que observaram decréscimo no teor de proteínas solúveis após a aplicação dos herbicidas butachlor, chlorimuron-ethyl e metribuzin em plantas de milho e trigo.

Às 24 HAA, não se observou efeito dos herbicidas sobre o teor de proteinas solúveis; contudo, às 48 HAA, o chlorimuron-ethyl elevou o teor de proteínas. Quando o teor de proteínas foi quantificado às $72 \mathrm{HAA}$, não houve diferença entre os tratamentos, assim como às 96 HAA.

Os teores de proteinas foram semelhantes entre as plantas não tratadas e as pulverizadas com os herbicidas inibidores da ALS. Já os herbicidas fomesafen e lactofen, inibidores da PROTOX, reduziram significativamente os teores de proteínas solúveis em relação à testemunha; o lactofen apresentou conteúdo de proteínas solúveis semelhante ao dos encontrados nas plantas tratadas com chlorimuron-ethyl e imazethapyr. Isso se deve, em parte, ao fato de que os herbicidas inibidores da PROTOX atacam e oxidam estas proteínas, resultando em perda da clorofila, dos carotenoides e pelo rompimento das membranas (Oliveira Junior, 2001), o que pode explicar a redução expressiva no teor de proteínas solúveis encontrado neste estudo.

O déficit hídrico não alterou o teor de proteínas solúveis nas plantas de I. grandifolia pulverizadas com os herbicidas inibidores da PROTOX e ALS (dados não demonstrados). Não houve interação entre os fatores herbicida e umidade, e os herbicidas inibidores da ALS proporcionaram maior concentração de aminoácidos livres nas plantas (Tabela 5).

A ação de chlorimuron-ethyl e imazethapyr nas plantas sugere que esses herbicidas podem diminuir o teor de proteínas, com consequente redução na formação dos aminoácidos valina, leucina e isoleucina, porém com aumento na concentração de outros aminoácidos (Shaner \& Reider, 1986; Scarponi et al., 1995; Martinetti et al., 1995).

Às 48 HAA, as concentrações de $\mathrm{N}-\alpha$-aminossolúvel nas plantas tratadas com os inibidores da PROTOX foram semelhantes à determinada na testemunha não tratada. Segundo Nemat Alla et al. (2008), o aumento de aminoácidos pode ser explicado pelo aumento no conteúdo de $\mathrm{N}$-solúvel; esse incremento em aminoácidos pode sugerir um aumento das proteólises. Evidências para o aumento de proteólises em plantas têm sido um indicativo em resposta de estresse biótico e abiótico (Aranha et al., 2007).

Às 72 HAA, a menor concentração de aminoácidos foi encontrada nas plantas não

Tabela 4 - Proteínas solúveis em plantas de Ipomoea grandifolia após a aplicação de herbicidas em diferentes épocas de avaliação. Botucatu-SP, 2010

\begin{tabular}{|c|c|c|c|c|c|}
\hline \multirow{3}{*}{ Herbicida } & \multirow{3}{*}{$\begin{array}{c}\text { Dose } \\
\left(\text { g i.a. } \text { ha }^{-1}\right)\end{array}$} & \multicolumn{4}{|c|}{ Proteínas solúveis } \\
\hline & & \multicolumn{4}{|c|}{$\left(\mathrm{mg} \mathrm{g}^{-1}\right.$ massa seca) } \\
\hline & & $24 \mathrm{HAA}$ & 48 HAA & 72 HAA & 96 HAA \\
\hline testemunha & - & $9,04^{\mathrm{ns}}$ & $8,79 \mathrm{~b}$ & $9,20^{\mathrm{ns}}$ & $10,91 \mathrm{a}$ \\
\hline fomesafen $^{\underline{1}}$ & 250 & 8,92 & $7,78 \mathrm{~b}$ & 8,93 & $4,46 \mathrm{c}$ \\
\hline lactofen & 180 & 8,79 & $8,02 \mathrm{~b}$ & 9,32 & $8,15 \mathrm{~b}$ \\
\hline 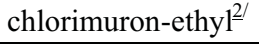 & 80 & 9,23 & $10,74 \mathrm{a}$ & 10,05 & $9,94 \mathrm{ab}$ \\
\hline imazethapyr & 100 & 8,04 & $8,97 \mathrm{~b}$ & 9,87 & $9,40 \mathrm{ab}$ \\
\hline $\mathrm{CV}(\%)$ & - & 15,3 & 12,5 & 13,2 & 15,4 \\
\hline
\end{tabular}

${ }^{n s}$ Não houve diferença significativa $(\mathrm{p} \leq 0,05)$ entre os tratamentos. ${ }^{1 /}$ Adicionou-se Agral $(0,1 \% \mathrm{v} / \mathrm{v}) ; \stackrel{2}{2}$ Adicionou-se Assist $(0,5 \% \mathrm{v} / \mathrm{v})$. Médias seguidas de mesma letra minúscula não diferem entre si pelo teste Tukey $(\mathrm{p} \leq 0,05)$. HAA - horas após a aplicação. 
tratadas, a qual não diferiu das tratadas com lactofen; o chlorimuron-ethyl foi o herbicida que proporcionou a maior concentração de aminoácidos livres. Às 96 HAA, entre os herbicidas testados, o fomesafen provocou a menor concentração de aminoácidos livres.

As plantas tratadas com inibidores da ALS, especialmente aquelas sob efeito de chlorimuron-ethyl apresentaram maior concentração de aminoácidos livres do que as tratadas com inibidores da PROTOX. De acordo com Nemat Alla et al. (2008), o aumento de aminoácidos ocorre basicamente com o decréscimo de proteínas; assim, isso se deve ao aumento dos aminoácidos aromáticos e alifáticos no tecido foliar, pela quebra dessas proteínas. Esses aminoácidos são componentes essenciais em proteinas e requeridos para a produção de novas células (Marchi et al., 2008).

Quanto ao efeito do déficit hídrico na ação dos herbicidas e consequentes alterações nas concentrações de aminoácidos livres (Tabela 6), no período de 48 HAA houve decréscimo na concentração de aminoácidos nas plantas de I. grandifolia sob déficit, sendo essa redução de $21 \%$. Também, às 72 HAA, essa concentração apresentou decréscimo de 17\%, mostrando que o déficit hídrico continuou a reduzir essa concentração. Já às 96 HAA, o déficit hídrico imposto às plantas passou a não mais influenciar a concentração de aminoácidos.

Portanto, os resultados obtidos neste trabalho indicam que em um solo sob condição de

Tabela 5 - N- $\alpha$-aminossolúvel em plantas de Ipomoea grandifolia após a aplicação de herbicidas em diferentes épocas de avaliação. Botucatu-SP, 2010

\begin{tabular}{|c|c|c|c|c|}
\hline \multirow[t]{2}{*}{ Herbicida } & \multirow{2}{*}{ 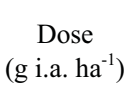 } & \multicolumn{3}{|c|}{$\begin{array}{c}\mathrm{N}-\alpha \text {-aminossolúvel } \\
\left(\mu \mathrm{mol} \mathrm{g} \mathrm{g}^{-1} \text { massa seca }\right)\end{array}$} \\
\hline & & 48 HAA & 72 HAA & $96 \mathrm{HAA}$ \\
\hline testemunha & - & $60,00 \mathrm{~b}$ & $44,51 \mathrm{c}$ & $44,25 \mathrm{c}$ \\
\hline fomesafen ${ }^{1 /}$ & 250 & $56,13 \mathrm{~b}$ & $64,27 \mathrm{ab}$ & $50,19 \mathrm{~b}$ \\
\hline lactofen & 180 & $59,75 \mathrm{~b}$ & $50,98 \mathrm{bc}$ & $50,70 \mathrm{bc}$ \\
\hline chlorimuron-ethyl ${ }^{2 /}$ & 80 & $89,38 \mathrm{a}$ & $80,99 \mathrm{a}$ & $74,21 \mathrm{a}$ \\
\hline imazethapyr & 100 & $97,50 \mathrm{a}$ & $65,73 \mathrm{ab}$ & $62,97 \mathrm{ab}$ \\
\hline $\mathrm{CV}(\%)$ & - & 24,6 & 21,9 & 15,6 \\
\hline
\end{tabular}

${ }^{1 /}$ Adicionou-se Agral (0,1\% v/v). ${ }^{2 /}$ Adicionou-se Assist (0,5\% v/v). Médias seguidas de mesma letra não diferem entre si pelo teste Tukey (p $\leq 0,05)$. HAA - horas após a aplicação.
Tabela 6 - N- $\alpha$-aminossolúvel em plantas de Ipomoea grandifolia submetidas à aplicação de herbicidas sob duas condições de déficit hídrico. Botucatu-SP, 2010

\begin{tabular}{|l|c|c|c|}
\hline \multirow{2}{*}{ Condição hídrica } & \multicolumn{3}{|c|}{$\begin{array}{c}\text { N- } \alpha \text {-aminossolúvel } \\
\left(\mu \mathrm{mol} \mathrm{g} \mathrm{g}^{-1} \text { massa seca }\right)\end{array}$} \\
\cline { 2 - 4 } & $48 \mathrm{HAA}$ & $72 \mathrm{HAA}$ & $96 \mathrm{HAA}$ \\
\hline Sem estresse & $81,15 \mathrm{a}$ & $66,85 \mathrm{a}$ & $59,15^{\text {ns }}$ \\
\hline Com estresse & $63,95 \mathrm{~b}$ & $55,74 \mathrm{~b}$ & 53,78 \\
\hline \multicolumn{1}{|c|}{ CV (\%) } & 24,6 & 21,9 & 15,6 \\
\hline
\end{tabular}

${ }^{\text {ns }}$ Não houve diferença significativa $(\mathrm{p} \leq 0,05)$ entre os tratamentos. Médias seguidas de mesma letra não diferem entre si pelo teste Tukey $(p \leq 0,05)$. HAA - horas após a aplicação.

déficit hídrico devem-se utilizar preferencialmente herbicidas inibidores da PROTOX no controle de plantas I. grandifolia. Caso se utilizem herbicidas inibidores da ALS nessa condição, o chlorimuron-ethyl apresentou-se como uma opção menos eficiente de controle do que o imazethapyr. Quanto aos solutos orgânicos analisados, o conteúdo de carboidratos e aminoácidos foi afetado pela ação dos herbicidas e pelo déficit hídrico do solo; e o teor de proteína solúvel foi reduzido pela atuação dos herbicidas inibidores da PROTOX.

\section{LITERATURA CITADA}

ARANHA, M. M. et al. Dinitro-o-cresol induces apoptosislike cell death but not alternative oxidase expression in soybean cells, J. Plant Physiol., v. 164, n. 6, p. 675-684, 2007.

BRADFORD, M. A rapid and sensitive method for quatitation of microgram quantities of protein utilizing the principle-dye binding. Anal. Biochem., v. 72, n. 1-2, p. 248-254, 1976.

BRAY, E. A. Plant responses to water deficit. Trends Plant Sci., v. 2, n. 2, p. 48-54, 1997.

CARVALHO, W. A.; ESPÍNDOLA, C. R.; PACOLLA, A. A. Levantamento de Solos da Fazenda Lageado-Estação Experimental "Presidente Médici”. Botucatu: UNESP/ FCA, 1983. 95 p.

DUBOIS, M. et al. Colorimetric method for determination of sugars and related substances. Anal. Chem., v. 28, n. 3, p. 350-356, 1956.

\section{EMPRESA BRASILEIRA DE PESQUISA} AGROPECUÁRIA - EMBRAPA. Centro Nacional de Pesquisa do Solo. Sistema brasileiro de classificação de solos. Brasília: Embrapa Produção de Informação; Rio de Janeiro: Embrapa Solos, 1999. 412 p. 
FUNKHOUSER, E. A. et al. Cellular and molecular responses to water deficits stress in woody plants. In: PESSARALAKLI, M. (Ed.) Handbook of plant and crop stress. New York, Marcel Dekker, 1994. p. 347-362.

KRAMER, P. J. Water relations of plants and soils. London: Academic Press, 1995. 495 p.

LECOEUR, J.; SINCLAIR, R. T. Field pea transpiration and leaf growth in response to soil water deficits. Crop Sci., v. 36, n. 2, p. 331-335, 1996.

MARCHI, G.; MARCHI, E. C. S.; GUIMARÃES, T. G. Herbicidas: mecanismo de ação e uso. Planaltina: Embrapa Cerrados, 2008. (Documentos, 227)

MARTINETTI, L.; SCARPONI, L.; NEMAT ALLA, M.M. Effect of rimsulfuron and its major degradation product on ALS activity and on protein and starch formation in maize. In: Brighton crop protection conference: weeds, Farnham, 1, 1995. Brighton. British Crop Protection Council... Brighton (United Kingstom), v. 1, p. 405-410, 1995.

MORGAN, J. M. Osmorregulation and water stress in higher plants. Ann. Rev. Plant Physiol., v. 35, n. 1, p. 299-319, 1984

MUNNS, R. Comparative physiology of salt and water stress. Plant, Cell and Environment, v. 25, n. 2, p. 239-250, 2002.

NEMAT ALLA, M. M. et al. Effect of metribuzin, butachlor and chlorimuron-ethyl on amino acid and protein formation in wheat and maize seedlings. Pest. Biochem. Physiol., v. 90, n. 1, p. 8-18, 2008.

OLIVEIRA JR., R. S. Mecanismo de ação de herbicidas. In: OLIVEIRA JR., R. S.; CONSTANTIN, J. (Coord.). Plantas daninhas e seu manejo. Guaíba: Agropecuária, 2001. p. 209-260.

PEREGOY, R. et al. Moisture stress effects on the absorption, translocation, and metabolism of haloxyfop in johnsongrass (Sorghum halepense) and large crabgrass (Digitaria sanguinalis). Weed Sci., v. 38, n. 4-5, p. 331-337, 1990.
PEREIRA, M. R. R. Potenciais hídricos no solo sobre a eficácia de herbicidas em plantas daninhas monocotiledôneas. 2010. 175 f. Tese (Doutorado em Agronomia) - Universidade Estadual Paulista, Botucatu, 2010.

PIMENTEL, C. Relações hídricas em dois híbridos de milho sob dois ciclos de deficiência hídrica. Pesq. Agropec. Bras., v. 34, n. 11, p. 2021-2027, 1999.

ROMAN, E. S.; VARGAS, L.; RIBEIRO, M. C. F. Efeito do teor de umidade do solo na seletividade e na eficácia de carfentrazone-ethyl no controle de plantas daninhas na cultura da soja. R. Bras. Herbic. Passo Fundo, 2005. Disponível em: <htpp://www.upf.br/rbherbicidas/download/ rbh_carfentrazone.pdf $>$. Acesso em: 19 out. 2010.

SCARPONI, L. et al. Effects of chlorimuron-ethyl, imazethapyr and propachlor on free amino acids e protein formation in Vicia faba L. J. Agric. Food Chem., v. 45, n. 9, p. 3652-3658, 1997.

SHANER, D. L.; REIDER, M. L. Physiological responses of corn (Zea mays) to AC-243,997 in combination with valine, leucine and isoleucina. Pest. Biochem. Physiol., v. 25, n. 2, p. 248-257, 1986.

SOCIEDADE BRASILEIRA DA CIÊNCIA DAS PLANTAS DANINHAS - SBCPD. Procedimentos para instalação, avaliação e análise de experimentos com herbicidas. Londrina: 1995.42 p.

TAIZ, L.; ZEIGER, E. Fisiologia vegetal. Porto Alegre: Artmed, 2004. 719 p.

VOLL, E. et al. Competição relativa de espécies de plantas daninhas com dois cultivares de soja. Planta Daninha, v. 20, n. 1, p. 17-24, 2002.

YEMM, E. W.; COCKING, E. F. The determination of amino acids with ninhydrin. Analyst, v. 80, n. 948, p. 209-213, 1955. 